\title{
Effects of Oracy Building Instruction via Blended Learning Environment on Eil Students' Oracy Skills
}

\author{
Dr.Pornpimol Sukavatee and Kusuma Bangkom
}

Chulalongkorn University

\begin{abstract}
The study aims to develop oracy building instruction in a blended-learning environment and to investigate the effects of students' oracy skills after implementing the speaking and listening building instruction via blended-learning environment. Twenty-nine high school students in a public school in Rayong were chosen as the sample group.The finding reveals that there was a significant improvement of the participants' English oracy skills after taking the course, and the students had positive opinions towards oracy building instruction via blended-learning environment. This research provides empirical evidence for the effectiveness of blendedlearning environment and gives useful insights for future students, teachers, and institutions in teaching oracy skills of English.
\end{abstract}

Keywords: active listening; online; oracy building teaching cycle; speaking; self-awareness 